\title{
Successful Management of Cap Polyposis with Eradication of Helicobacter pylori Relapsing 15 Years after Remission on Steroid Therapy
}

\author{
Fuminao Takeshima, Takemasa Senoo, Kayoko Matsushima, Yuko Akazawa, \\ Naoyuki Yamaguchi, Ken Shiozawa, Ken Ohnita, Tatsuki Ichikawa, \\ Hajime Isomoto and Kazuhiko Nakao
}

\begin{abstract}
A 37-year-old woman was evaluated at our hospital for a treatment-resistant proctosigmoiditis. Fifteen years previously, ulcerative colitis was suspected and she was cured by steroid therapy. Colonoscopy revealed multiple sessile polyps covered with white exudate from the rectum to the sigmoid colon. Histopathological examination revealed a mucosal surface cover of granulation tissue. Based on these findings, cap polyposis was diagnosed. She underwent Helicobacter pylori eradication therapy, and at 1 month after therapy, her symptoms had improved. We present a case of cap polyposis relapsing 15 years after remission with steroid therapy, and that was improved by $H$. pylori eradication therapy.
\end{abstract}

Key words: cap polyposis, Helicobacter pylori infection, eradication therapy

(Intern Med 51: 435-439, 2012)

(DOI: 10.2169/internalmedicine.51.6376)

\section{Introduction}

Cap polyposis was first described in 1985 by Williams et al (1) as an unusual inflammatory bowel disease. They reported inflammatory polyps characterized histopathologically by the presence of "caps" of granulation, which cover the tops of polyps. The clinical course and pathogenesis of this disease are yet to be elucidated, and specific therapies have not been established (2). However, there have been several case reports of cap polyposis being improved by eradication of Helicobacter pylori (3-5). In this report, we present a case of cap polyposis that relapsed after 15 years of remission by steroid therapy, and that was cured by H. pylori eradication therapy.

\section{Case Report}

A 37-year-old woman was evaluated at our hospital for a 5-month history of treatment-resistant proctosigmoiditis. In
March 2010, the patient developed diarrhea (10 times/day) and mucous bloody stools. Total colonoscopy at another hospital showed an inflamed area with multiple reddened and eroded lesions from the rectum to the sigmoid colon. She was treated with $2,250 \mathrm{mg}$ of oral aminosalicylic acid for four weeks without improvement. As an additional 20 $\mathrm{mg}$ of oral prednisolone for two weeks did not provide any further symptomatic relief, she was referred to our hospital in August 2010.

In 1995, she experienced similar symptoms, including diarrhea and mucous bloody stools, and total colonoscopy (Fig. 1A) revealed an inflamed area with multiple reddened and eroded lesions in the rectum to the sigmoid colon; thus, ulcerative colitis was suspected. She was treated by $20 \mathrm{mg}$ of oral prednisolone for 1 month and was weaned off over 3 months. Her symptoms disappeared and total colonoscopy in 1996 revealed some improvements, although some red spots and erosions remained (Fig. 1B). No clinical recurrence was observed for 15 years.

On physical examination, her abdomen was soft and there 

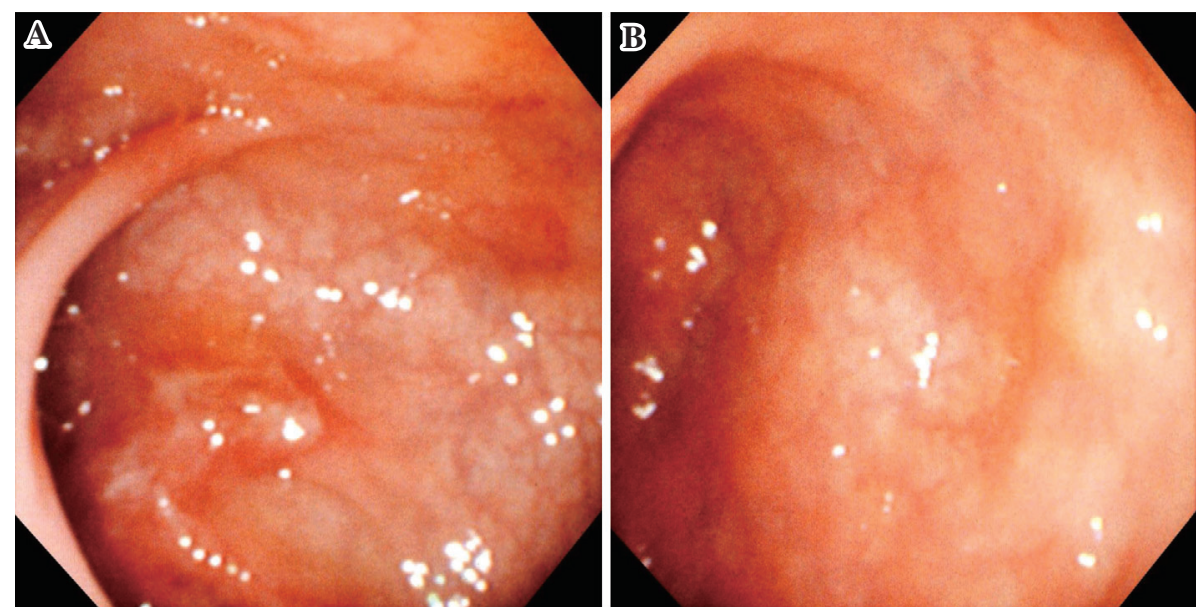

Figure 1. Colonoscopy from 1995 (A) showing inflamed area with multiple reddened and eroded lesions with normal intervening mucosa from the rectum to the sigmoid colon. Colonoscopy from 1996 (B) showing improvement of the lesion in the rectum.
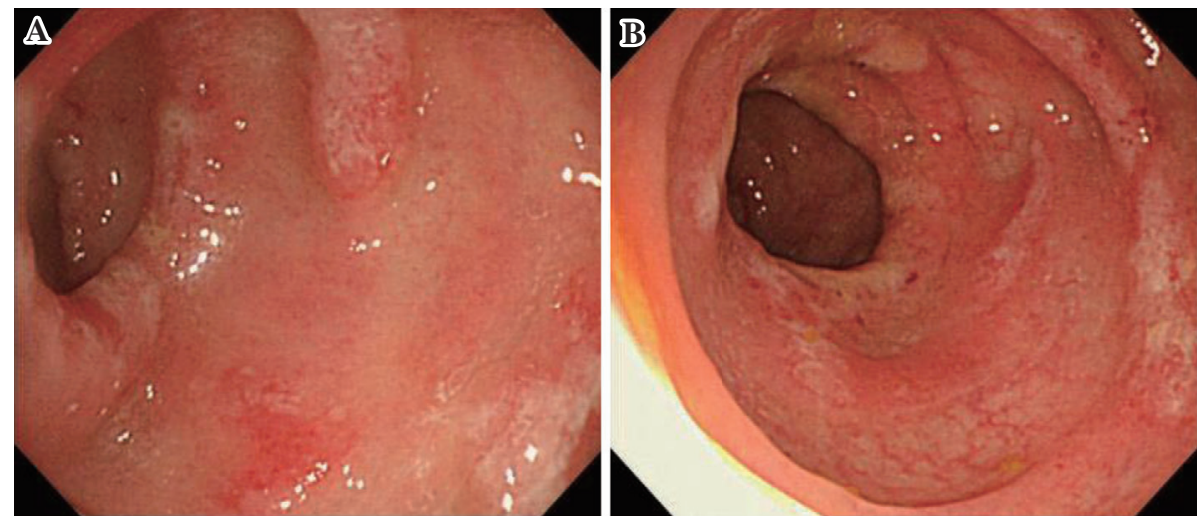

Figure 2. Colonoscopy from August 2010 revealed multiple reddened and eroded sessile polyps covered with white purulent exudate, located at the apices of transverse mucosal folds of the rectum (A) and sigmoid colon (B).

was no tenderness or palpable mass. Laboratory studies showed normal hemoglobin $(13.3 \mathrm{~g} / \mathrm{dL})$ and white blood cell count $\left(4,500 / \mathrm{mm}^{3}\right)$. Total serum protein was slightly decreased $(6.4 \mathrm{~g} / \mathrm{dL}$ with $3.6 \mathrm{~g} / \mathrm{dL}$ albumin), while C-reactive protein levels were not elevated $(0.2 \mathrm{mg} / \mathrm{dL})$. Fecal culture revealed no pathogenic organisms.

Total colonoscopy in August 2010 (Fig. 2) revealed multiple reddened and eroded sessile polyps covered with white purulent exudate and located at the apices of transverse mucosal folds of the rectum and sigmoid colon. The intervening mucosa between the lesions was normal and the remainder of the colon to the cecum and the terminal ileum were also normal.

Histopathological examination of biopsy specimens from the lesions (Fig. 3A) revealed a mucosal surface covered by 'caps' of inflammatory granulation tissue, as well as elongated and branched crypts, while specimens from the intervening mucosa between lesions were normal (Fig. 3B). Based on these findings, cap polyposis was diagnosed. Because she tended to strain at defecation, we first educated her on bowel habitual correction in order to avoid straining at defecation. After 2 months of this management, there was no improvement in clinical symptoms.

Esophagogastroduodenoscopy in October 2010 revealed atrophic gastritis, and she was diagnosed with $H$. pylori infection based on rapid urease test results and elevated antiH. pylori $\mathrm{IgG}$ antibody levels $(134 \mathrm{U} / \mathrm{mL}$; reference range, $<10 \mathrm{U} / \mathrm{mL}$ ). After providing informed consent, she underwent eradication therapy with $20 \mathrm{mg}$ of rabeprazole, 1,500 $\mathrm{mg}$ of amoxicillin and $800 \mathrm{mg}$ of clarithromycin daily for 7 days. Eradication therapy was successful and at about 1 month after therapy, her symptoms, including mucous bloody stool and diarrhea, had improved markedly. Total colonoscopy in January 2011 (Fig. 4) confirmed that the multiple sessile polyps had disappeared.

\section{Discussion}

The etiology of cap polyposis is unclear, but various possible causes, including infection (6), mucosal ischemia (7), 


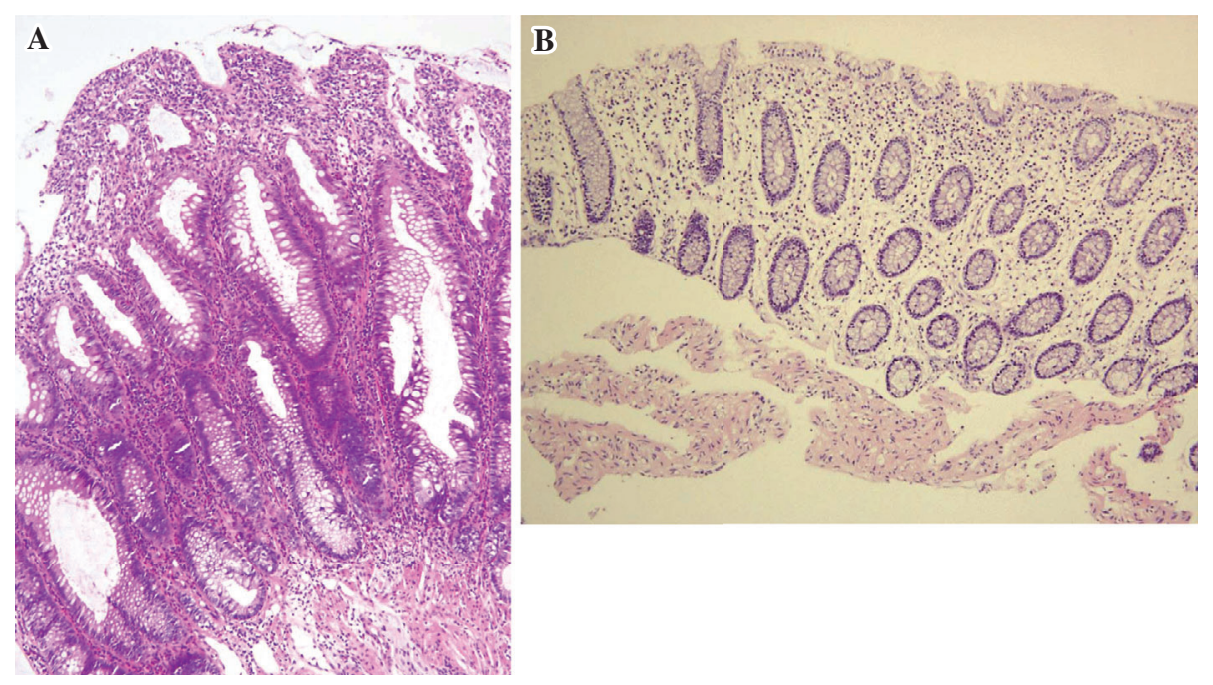

Figure 3. Histopathological section of biopsy specimens from the rectum (A) revealed a mucosal surface covered by "caps" of inflammatory granulation tissue, and elongated and branched crypts, but specimens from intervening mucosa between the lesions (B) showed normal findings (Hematoxylin and Eosin staining).

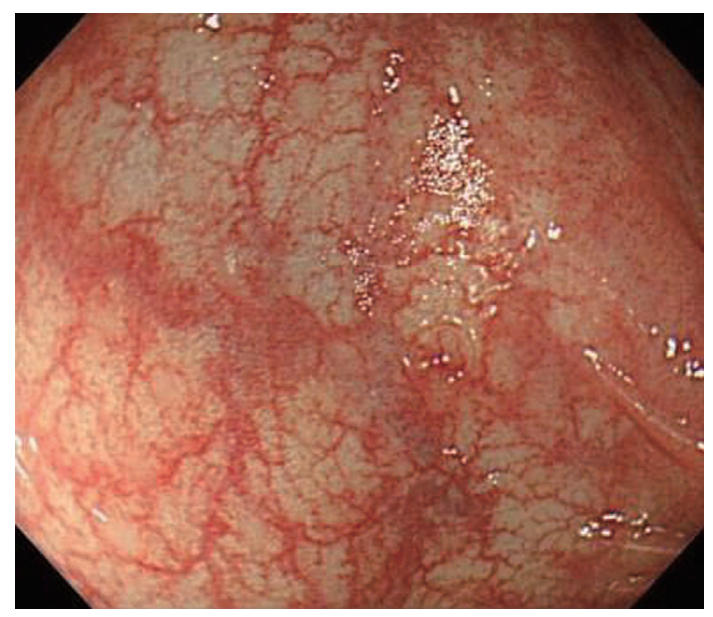

Figure 4. Colonoscopy after $\boldsymbol{H}$. pylori eradication confirmed that multiple sessile polyps had disappeared.

T cell-mediated inflammation (8), mechanical stimulation by abnormal bowel motility and repeated trauma to the colonic mucosa caused by straining (9) have been proposed. Although various medical treatments based on the etiological hypothesis had been advocated, optical treatment has not yet been established. Metronidazole has been useful in some cases $(10,11)$, but not in others $(4,7,8,12)$. Shimizu et al (11) speculated that the role of metronidazole may be related to its anti-inflammatory action rather than its antibiotic action against specific pathogens. Several reports (9) have recommended avoidance of straining at defecation, but in most cases $(4,5,13)$, including the present case, the effect is temporal or absent. Recently, Bookman et al (8) demonstrated that infusion with infliximab resulted in complete remission, and Kim et al (12) reported a case resolved by treatment with infliximab that maintained remission for 3 years. In contrast, another study (13) observed no effect from treatment with infliximab.

Since Oiya et al (3) reported a case of cap polyposis treated successfully by eradication of $H$. pylori, $H$. pylori infection has been suggested to be related to cap polyposis. We identified five cases of cap polyposis treated by $H$. $p y$ lori eradication in a MEDLINE search of the English literature (3-5), and all of these are from Japan. If we include the Japanese literature with English abstracts on Ichushi Web by the Japan Medical Abstracts Society (14-17) and our own cases, there have been 10 cases of cap polyposis treated by H. pylori eradication (Table 1). All of these were diagnosed as $H$. pylori infection by histology, culture or rapid urease test of gastric biopsy, or urease breath test, and eradication therapy was successful in all cases. After successful eradication therapy, clinical symptoms improved and the disappearance of polypoid lesions was confirmed by endoscopy in all cases. Moreover, no recurrence has been reported.

Akamatsu et al (4) reported that $H$. pylori was not detected in the colonic mucosa on immunohistochemical study using anti-H. pylori antibody, and in other cases, $H$. pylori was not detected in the colonic mucosa by histological study. The possible role of $H$. pylori in extragastric diseases, such as idiopathic thrombocytopenic purpura (ITP), iron deficiency anemia, chronic urticaria and ischemic heart disease, has been suggested (18). CagA, which is a virulent protein expressed by $H$. pylori has been suggested to play a role in ITP because most patients who responded to eradication therapy have the anti-CagA antibody (19). Although $H$. pylori was not detected on colonic mucosa, cap polyposis may have an extragastric manifestation of $H$. pylori. Based on the effects of eradication in all reported cases, we strongly recommend testing for $H$. pylori infection, and that eradication therapy should be administered in $H$. pyloripositive cases with cap polyposis.

Because the present patient experienced similar symptoms 
Table 1. Case Reports of Cap Polyposis Treated by Helicobacter pylori Eradication

\begin{tabular}{|c|c|c|c|c|c|}
\hline Case & Gender & Age & Location & $\begin{array}{l}\text { HP } \\
\text { infection }\end{array}$ & result \\
\hline $\begin{array}{l}\text { Oiya } \\
(2002)\end{array}$ & $\mathrm{M}$ & 63 & RSDTA & + & resolved \\
\hline $\begin{array}{l}\text { Akamatsu } \\
(2004)\end{array}$ & W & 33 & $\mathrm{R}$ & + & resolved \\
\hline $\begin{array}{l}\text { Akamatsu } \\
(2004)\end{array}$ & $\mathrm{W}$ & 50 & $\mathrm{RS}$ & + & resolved \\
\hline $\begin{array}{l}\text { Akamatsu } \\
(2004)\end{array}$ & $\mathrm{W}$ & 53 & $\mathrm{RS}$ & + & resolved \\
\hline $\begin{array}{l}\text { Takayama } \\
(2008)\end{array}$ & $\mathrm{W}$ & 59 & $\mathrm{RS}$ & + & resolved \\
\hline $\begin{array}{l}\text { Yoshino } \\
(2009)\end{array}$ & W & 7 & $\mathrm{RS}$ & + & resolved \\
\hline $\begin{array}{l}\text { Takao } \\
(2009)\end{array}$ & $\mathrm{W}$ & 55 & $\mathrm{R}$ & + & resolved \\
\hline $\begin{array}{l}\text { Nakagawa } \\
(2009)\end{array}$ & W & 52 & RSDT & + & resolved \\
\hline $\begin{array}{l}\text { Ishikawa } \\
\text { (2010) }\end{array}$ & W & 68 & $\mathrm{RS}$ & + & resolved \\
\hline $\begin{array}{l}\text { Our case } \\
(2011)\end{array}$ & $\mathrm{W}$ & 37 & $\mathrm{RS}$ & + & resolved \\
\hline
\end{tabular}

in 1995 and 2010, and because colonoscopy in 1995 revealed an inflamed area with multiple reddened and eroded lesions with normal intervening mucosa from the rectum to the sigmoid colon, we believe that she suffered from cap polyposis, not ulcerative colitis, in 1995, which then relapsed in 2010 at 15 years after remission was induced by steroid therapy. The reason steroid therapy improved the lesions in 1995, but had no effect in 2010 is unclear, but it is possible that our patient had a more refractory form of the disease after relapse. When we treat patients with inflammatory bowel disease, larger amounts of steroids are sometimes needed to treat relapse when compared with the initial attack, or additional therapy is necessary. Although steroids are administered in many cases of cap polyposis, only temporal improvement is seen in a few cases (4).

The clinical course and long-time prognosis of cap polyposis remain unknown. Maunoury et al (20) reported a case of cap polyposis that relapsed at 5 years after sigmoid resection. Konishi et al (21) also demonstrated that cap polyposis recurred at 3 months after sigmoid colectomy and improved spontaneously within 3 months. Nakagawa et al (5) reported a case of cap polyposis relapsing at 3 years after remission by avoiding straining at defecation. We believe that in the present case eradication of $H$. pylori resolved cap polyposis, but not spontaneously, as 2 months of avoiding straining at defecation did not provide any symptomatic relief, although most of the patients that improved without any medication tended to strain $(9,22)$. Moreover, the 7 -month history of symptoms diminished at only 1 month after eradication of $H$. pylori and endoscopic remission was confirmed at only 3 months after treatment. Analysis of additional cases is therefore necessary to elucidate clinical course and prognosis, and we plan to continue to follow this case carefully.

The authors state that they have no Conflict of Interest (COI).

\section{References}

1. Williams GT, Bussey HJR, Morson BC. Inflammatory cap polyps of the large intestine. Br J Surg 72: S133, 1985.

2. Ng KH, Mathur P, Kumarasinghe MP, Eu KW, Seow-Choen F. Cap polyposis: further experience and review. Dis Colon Rectum 47: 1208-1215, 2004.

3. Oiya H, Okawa K, Aoki T, et al. Cap polyposis cured by Helicobacter pylori eradication therapy. J Gastroenterol 37: 463-466, 2002.

4. Akamatsu T, Nakamura N, Kawamura Y, et al. Possible relationship between Helicobacter pylori infection and cap polyposis of the colon. Helicobacter 9: 651-656, 2004.

5. Nakagawa $\mathrm{Y}$, Nagai $\mathrm{T}$, Okawara $\mathrm{H}$, et al. Cap polyposis (CP) which relapsed after remission by avoiding straining at defecation, and was cured by Helicobacter pylori eradication therapy. Intern Med 48: 2009-2013, 2009.

6. Gehenot M, Colombel JF, Wolschies E, et al. Cap polyposis occurring in the postoperative course of pelvic surgery. Gut 35: 1670-1672, 1994.

7. Oshitani N, Moriyama Y, Matsumoto T, et al. Protein-losing enteropathy from cap polyposis. Lancet 346: 1567, 1995.

8. Bookman ID, Redston MS, Greenberg GR. Successful treatment of cap polyposis with infliximab. Gastroenterology 126: 18681871, 2004.

9. Oriuchi T, Kinouchi Y, Kimura M, et al. Successful treatment of cap polyposis by avoidance of intraluminal trauma: clues to pathogenesis. Am J Gastroenterol 95: 2095-2098, 2000.

10. Esaki M, Matsumoto T, Kobayashi $\mathrm{H}$, et al. Cap polyposis of the colon and rectum: an analysis of endoscopic findings. Endoscopy 33: 262-266, 2001.

11. Shimizu K, Koga H, Iida M, et al. Does metronidazole cure cap polyposis by its antiinflammatory actions instead of by its antibiotic action? A case study. Dig Dis Sci 47: 1465-1468, 2002.

12. Kim ES, Jeen YT, Keum B, et al. Remission of cap polyposis maintained for more than three years after infliximab treatment. Gut Liver 3: 325-328, 2009.

13. Maunoury V, Breisse M, Desreumaux P, Gambiez L, Colombel JF. Infliximab failure in cap polyposis. Gut 54: 313-314, 2005.

14. Takayama R, Nakamura $T$, Tajika $M$, et al. A case of cap polyposis cured by $\mathrm{H}$. pylori eradication therapy. Gastroenterol Endosc 50: 2705-2711, 2008 (in Japanese, Abstract in English).

15. Yoshino S, Hirakawa K, Himeno Y, et al. Regression of cap polyposis after eradication of Helicobacter pylori: report of a child case. Gastroenterol Endosc 51: 368-373, 2009 (in Japanese, Abstract in English).

16. Takao M, Hashimoto T, Sakaguchi M, et al. A case of cap polyposis effectively treated by Helicobacter pylori eradication. Gastroenterol Endosc 51: 1323-1328, 2009 (in Japanese, Abstract in English).

17. Ishikawa $M$, Yoneda $T$, Nakazawa $T$, et al. A case of cap polyposis cured by Helicobacter pylori eradication therapy. J Jpn Surg Assoc 71: 2661-2664, 2010 (in Japanese, Abstract in English).

18. Figura N, Franceschi F, Santucci A, et al. Extragastric manifestations of Helicobacter pylori infection. Helicobacter 15(Suppl 1): 60-68, 2010.

19. Scandellari R, Allemand E, Vettore $S$, et al. Platelet response to Helicobacter pylori eradication therapy in adult chronic idiopathic thrombocytopenic purpura seems to be related to the presence of anticytotoxin-associated gene A antibodies. Blood Coagul Fibrinolysis 20: 108-113, 2009. 
Intern Med 51: 435-439, 2012 DOI: 10.2169/internalmedicine.51.6376

20. Maunoury V, Breisse $M$, Desreumaux $P$, et al. Infliximab failure in cap polyposis. Gut 54: 313-314, 2005.

21. Konishi T, Watanabe T, Takei $\mathrm{Y}$, et al. Confined progression of cap polyposis along the anastomotic line, implicating the role of inflammatory responses in the pathogenesis. Gastrointest Endosc 62: 446-447, 2005.
22. Ohkawara T, Kato M, Nakagawa $S$, et al. Spontaneous resolution of cap polyposis: case report. Gastrointest Endosc 57: 599-602, 2003.

(C) 2012 The Japanese Society of Internal Medicine http://www.naika.or.jp/imindex.html 